\title{
Assessment of obesity and fear of fatness among inner-city Dublin schoolchildren in a one-year follow-up study
}

\author{
Anne C Griffin ${ }^{1}$, Katherine M Younger ${ }^{1}$ and Mary AT Flynn ${ }^{2, *}$ \\ 'School of Biological Sciences, Faculty of Science, Dublin Institute of Technology, Kevin Street, Dublin 8, \\ Republic of Ireland: ${ }^{2}$ Nutrition and Active Living, Health Promotion and Disease Prevention, Calgary Health Region, \\ 1509 Centre Street SW, PO Box 4016, Station 'C', Alberta, Canada, T2T 5TI
}

Submitted 28 August 2003: Accepted 27 January 2004

\begin{abstract}
Background: Positive secular trends in adolescent obesity and an increased prevalence of fear of fatness, particularly among girls, have been documented world-wide. There is a lack of consensus about assessment criteria for childhood obesity and no standard exists for assessing Irish children. In 1990, the Irish National Nutrition Survey used body mass index (BMI) $\geq 26 \mathrm{~kg} \mathrm{~m}^{-2}$ to describe the prevalence of overweight among Irish adolescents.

Objectives: (1) To examine the range in classification of Dublin schoolchildren as overweight according to four standard assessment methods; (2) to assess changes in weight status, prevalence of fear of fatness and accompanying slimming practices in a one-year follow-up; and (3) to compare the prevalence of overweight with that documented in 1990 among adolescents of similar age.

Design: A one-year follow-up study of 199 healthy schoolchildren (90 boys and 109 girls; mean age of 11 years at baseline) attending seven fee-paying (six single- and one mixed-sex) and eight non-fee-paying (four single- and four mixed-sex) primary schools in Dublin city centre.

Measurements: Weight, height, waist circumference and triceps skinfold were measured and used in five definitions of overweight, including published cut-off points of BMI-for-age (Centers for Disease Control and Prevention BMI-for-age charts for boys and girls; BMI reference curves for the UK 1990; International Obesity Task Force age- and sex-specific BMI cut-offs), actual relative weight and BMI $\geq 26$ $\mathrm{kg} \mathrm{m}^{-2}$. Assessment of body image perceptions and satisfaction (using figure line drawings) was reported in a questionnaire specifically designed for this study.

Results: The prevalence of overweight within the total group differed between the four standard definitions of weight status, by $9 \%$ at baseline and $8 \%$ at follow-up. Accordingly, increasing trends over the year ranged from zero to 3\%. Using the criterion $\mathrm{BMI} \geq 26 \mathrm{~kg} \mathrm{~m}^{-2}, 6 \%$ of Dublin schoolchildren were overweight, compared with $1.9 \%$ of schoolchildren in 1990. Significantly more girls than boys were affected by fear of fatness and were trying to lose weight.

Conclusion: A standard method for assessment of weight status is urgently needed for the evaluation of obesity prevention initiatives among Irish schoolchildren. Such initiatives need to be sensitive to the pervasiveness of fear of fatness among adolescent girls.
\end{abstract}

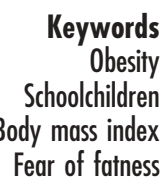

The prevalence of childhood obesity is described as being of epidemic proportions around the world ${ }^{1}$. The same serious long-term health problems caused by adult obesity are now found among overweight adolescents, fuelling the public health crisis ${ }^{2}$. There has been no new information on body weight status among young Irish schoolchildren since the Irish National Nutrition Survey (INNS) in 1990, when a cut-off of body mass index (BMI) at $26 \mathrm{~kg} \mathrm{~m}^{-2}$ identified $1.9 \%$ of schoolchildren (1.1\% of boys and $2.6 \%$ of girls) aged $12-15$ years as being at risk of overweight ${ }^{3}$.
Assessments of the prevalence and trends in childhood overweight have been difficult to conduct owing to a lack of international consensus on the criteria recommended for classifying individuals as overweight or obese ${ }^{4}$. Triceps skinfold closely relates to percentage body fat but is impracticable for epidemiological use $\mathrm{e}^{5,6}$. Weight-forheight indices are the most feasible and recently BMI has emerged as a means of defining overweight among children $^{7}$. Reference curves of BMI through childhood, that account for the substantial age-related changes, are 
necessary to assess BMI measurements ${ }^{8}$. Current published BMI-for-age cut-offs include those of the Centers for Disease Control and Prevention (CDC $)^{9}$, the BMI reference curves for the UK 1990 (UK90 charts) ${ }^{8}$ and the International Obesity Task Force (IOTF) ${ }^{6}$. Whereas the $\mathrm{CDC}^{9}$ in the USA and the UK90 charts ${ }^{8}$ in Great Britain are centile charts derived from national cross-sectional growth studies, the IOTF cut-offs are an internationally applicable standard derived from six large, nationally representative, cross-sectional growth studies ${ }^{6}$. Obesity is defined as a BMI-for-age above the 95th centile according to the CDC and above the 98th centile according to the UK90 charts. These and the relevant IOTF cut-offs that correspond to 11- and 12-year-old boys and girls are presented in Table 1. The concern with having a variety of cut-offs for assessing overweight in the same population is that the prevalence of overweight will vary according to the reference applied. There are no BMI cut-offs representative of an Irish population. Irish growth charts are currently limited to weight and height centiles ${ }^{10}$. As a result, the estimation of actual relative weight (ARW) is the only assessment of childhood obesity prevalence that uses a referent Irish population. ARW is the observed body weight of a child expressed as a percentage of ideal body weight for height, age and sex using appropriate growth references ${ }^{11,12}$.

BMI does not describe abdominal adiposity. Abdominal distribution of body fat and cardiovascular risk factors track from childhood to adulthood, and the identification of children with high abdominal adiposity is advantageous ${ }^{13}$. Recent studies in children show that a greater distribution of body fat in the abdomen is

Table 1 The range in published cut-off points (either a given number or derived from reference centile charts), based on weight-forheight measurements, that are currently advised for defining risk of overweight and actual overweight among children and adolescents

\begin{tabular}{llcc}
\hline & & \multicolumn{2}{c}{ Cut-off } \\
\cline { 3 - 4 } Weight-for- & & $\begin{array}{c}\text { Risk of } \\
\text { overweight }\end{array}$ & Overweight \\
height index & & $111-120$ & $>120$ \\
ARW $(\%)$ & $2-18$ years & 20.2 & 23.1 \\
CDC $\left(\mathrm{kg} \mathrm{m}^{-2}\right)^{*}$ & Males: age 11 years & 24.1 \\
& Females: age 11 years & 20.8 & 24.3 \\
& Males: age 12 years & 21.0 & 24.3 \\
& Females: age 12 years & 21.7 & 25.2 \\
$\mathrm{UK90}\left(\mathrm{kg} \mathrm{m}^{-2}\right) \dagger$ & Males: age 11 years & 20.1 & 22.6 \\
& Females: age 11 years & 21.2 & 23.8 \\
& Males: age 12 years & 20.8 & 23.4 \\
IOTF $\left(\mathrm{kg} \mathrm{m}^{-2}\right)$ & Females: age 12 years & 21.9 & 24.8 \\
& Males: age 11 years & 20.6 & 25.1 \\
& Females: age 11 years & 20.7 & 25.4 \\
& Males: age 12 years & 21.2 & 26.0 \\
& Females: age 12 years & 21.7 & 26.7 \\
\hline
\end{tabular}

ARW - actual relative weight ${ }^{10} ; \mathrm{CDC}$ - Centers for Disease Control and Prevention body mass index (BMI)-for-age charts for boys and girls ${ }^{9}$; UK90 - BMI reference curves for the UK $1990^{8}$; IOTF - International Obesity Task Force age- and sex-specific BMI cut-offs ${ }^{6}$.

${ }^{*}$ Risk of overweight taken as $\geq 85$ th centile and $<95$ th centile; overweight taken as $\geq 95$ th centile ${ }^{9}$.

†Risk of overweight taken as $\geq 91$ st centile and $<98$ th centile; overweight taken as $\geq 98$ th centile ${ }^{8}$. correlated with less favourable patterns of serum lipoprotein concentrations and blood pressure ${ }^{14}$. Recently, waist circumference has been shown to be a superior indicator of abdominal adiposity among children $^{15}$.

Concurrent with the increasing prevalence of obesity among children is a fear of fatness, particularly among young adolescent girls ${ }^{16}$. Unhealthy eating and disordered eating behaviours among young adolescents have the potential to adversely affect nutrient intake, mental health status and long-term health outcomes ${ }^{17}$. Compared with those who do not diet, adolescent girls who diet at a severe level are 18 times more likely, and those who diet at a moderate level five times more likely, to develop an eating disorder ${ }^{18}$

The purposes of this study were threefold. First, to examine the range in classification of Dublin schoolchildren as overweight according to four standard assessment methods, namely three published cut-off points of BMI-for-age ( $\mathrm{CDC}^{9}$, $\mathrm{IOTF}^{6}, \mathrm{UK}^{8} 0^{8}$ ) and $\mathrm{ARW}^{11,12}$. Second, to assess changes in weight status, prevalence of fear of fatness and accompanying slimming practices in a one-year follow-up. Finally, to indicate trends over the past decade, the prevalence of children with $\mathrm{BMI} \geq 26 \mathrm{~kg} \mathrm{~m}^{-2}$ was compared with that documented in the INNS among adolescents of similar age $\mathrm{e}^{3}$.

\section{Subjects and methods}

\section{Subjects}

Ethical approval for this research was obtained from the Joint Research Ethics Committee of Saint James's Hospital and the Federated Dublin Voluntary Hospitals. A list of Dublin schools was obtained from the Department of Education and Science and those located in Dublin inner city were identified. Those that catered for special needs or the Irish language were excluded. Of 21 Dublin primary schools invited, $71 \%(n=15)$ agreed to participate which included seven fee-paying (FP; six single- and one mixedsex) and eight non-fee-paying (NFP; four single- and four mixed-sex) schools. Four hundred and seventy-six subjects, a response rate of $60 \%$, received parental consent. A representative random sample ( $42 \%$ of the children recruited; $n=199,90$ boys, 109 girls; $88 \mathrm{FP}, 111$ NFP; mean age of 11 years at baseline), controlled equally for sex and school type attended, participated in the study.

\section{Socio-economic class}

Socio-economic class (SEC) was classified according to the highest classed earner (usually a parent or guardian) in the household ${ }^{19}$.

\section{Antbropometry}

Two children at a time were measured in a private room at their school. Weight (to the nearest $0.1 \mathrm{~kg}$ ) of each subject was measured barefoot and in light indoor clothing using 
SECA weighing scales. Height (to the nearest $0.1 \mathrm{~cm}$ ) was measured using a Leicester Height Measure (CMS Equipment). ARW was calculated as observed body weight expressed as a percentage of ideal body weight for height, age and sex, using Irish growth charts ${ }^{10}$, and BMI was calculated from observed weight and height $\left(\mathrm{kg} \mathrm{m}^{-2}\right)$. ARW cut-offs to define underweight, normal weight and overweight in this study were set at $\leq 89 \%$, $90-110 \%$ and $\geq 111 \%$, respectively ${ }^{11}$. Table 1 gives the range of published cut-offs available to define the risk of overweight and actual overweight based on weight-forheight measurements in children at mean ages of 11 and 12 years. The proportions of children in the follow-up year (mean age 12 years) and children from the INNS $^{3}$ (age range $12-15$ years) who had $\mathrm{BMI} \geq 26 \mathrm{~kg} \mathrm{~m}^{-2}$ were compared with the aim to elucidate the trend since 1990.

Waist circumference (WC; to the nearest $\mathrm{mm}$ ) was measured at the minimum girth between the lower rib margin and the iliac crest over the naked site. Triceps were measured (to the nearest $0.1 \mathrm{~mm}$ ) at the mid-point of the back of the upper right $\mathrm{arm}^{20}$ using a Harpenden Skinfold Calliper (British Indicators Ltd). The mean of three measurements, which did not differ by more than $1.0 \mathrm{~mm}$, was used in analysis. In some cases an adequate measurement of skinfold could not be recorded due to the tightness of the subcutaneous fat to muscle $(6 \%(n=5)$ boys and 11\% $(n=12)$ girls at age 11 years, and $8 \%$ ( $n=7)$ boys and $15 \%(n=16)$ girls at age 12 years).

\section{Body image concerns}

Subjects completed a self-report questionnaire (approximately 20 minutes), specifically designed for this study, at their schools in an exam-type setting. The main investigator explained each question separately using an overhead projector and a standard script to ensure consistency and avoid possible misunderstanding of any question being asked. All questions included a 'Don't know' option. Body image concerns were recorded using sex-specific line drawings $^{21}$ illustrating seven body shapes ranging from severely underweight to severely overweight. The set of drawings applied in the current study was taken from an earlier study ${ }^{21}$ of body shape perceptions and preferences among 1118 preadolescent children (average age 8 years). In their development, the line drawings of children's figures were reviewed by child and adult jurors, pilot tested, and examined for test-retest reliability and criterion validity $^{21}$. Before data collection for the present study, the self-report questionnaire was tested-retested among Dublin schoolchildren ( $n=34,17$ male, 17 female; mean age 10.4 years; from a mixed, NFP school) not participating in this study. A high proportion (82\%) gave consistent answers to the body image and slimming practices questions on retest, indicating reliability.

Subjects circled the line drawing that corresponded to the answer they associated with the question asked. Accordingly, disparity of own body shape was identified when the perceived body shape ('Which one looks like you?') line drawing circled by a subject differed from their measured ARW category. Circling an identical line drawing for preferred body shape ('Which shape would you like to look like?') as that chosen for perceived body shape ('Which one looks like you?') indicated satisfaction with body shape. Circling a thinner or fatter figure for preferred body shape than that chosen for perceived body shape indicated dissatisfaction with a preference towards being thinner or fatter, respectively. The subjects were also asked to report if they had ever tried to lose weight and which weight reduction methods they had used ${ }^{22}$.

\section{Data management and statistical analysis}

All data were coded for entry into the Statistical Package for Social Sciences (SPSS) version 10.0 for Windows (SPSS Inc., Chicago, IL, USA). 'Don't know' and 'None of the above' answers were omitted from analysis. Variables that were not normally distributed (using KolmogorovSmirnov tests), which included BMI, triceps and WC, were transformed (by taking the reciprocal or log) to achieve a normal distribution. O'Hares ${ }^{19}$ social classes one and two, three and four, five and six were combined to form socio-economic classes one, two and three, respectively. The seven categories of body shape illustrated by the line drawings were combined to define three distinct groups: underweight, normal weight and overweight.

Comparisons for the total group and for each sex were made between baseline and follow-up using the following statistics as appropriate: Wilcoxon signed rank, paired $t$ test and McNemar. Variables were analysed according to sex and SEC using the chi-square, Mann-Whitney and independent $t$-test, as appropriate. Pearson's correlation was used to assess the strength of relationships between BMI and triceps skinfold. The proportions having BMI $\geq 26 \mathrm{~kg} \mathrm{~m}^{-2}$ and sample numbers from the current study and the INNS ${ }^{3}$ were used to calculate 95\% confidence intervals and difference in proportions. A significant difference was indicated by a $P$-value of $\leq 0.05$.

\section{Results}

Anthropometric measurements were taken on average 0.98 (standard deviation (SD) 0.1) years (range 0.75-1.23 years) apart. The mean (SD) weight and height among boys were $41.1(8.2) \mathrm{kg}$ and $1.50(0.07) \mathrm{m}$ at age 11 years; and 46.7 (98.8) $\mathrm{kg}$ and $1.57(0.08) \mathrm{m}$ at age 12 years. The mean (SD) weight and height among girls were 42.4 (8.5) $\mathrm{kg}$ and $1.49(0.07) \mathrm{m}$ at age 11 years; and 48.2 (9.2) $\mathrm{kg}$ and $1.55(0.07) \mathrm{m}$ at age 12 years. The height gained by the boys was significantly greater than that gained by the girls (0.07 (0.02) $\mathrm{m}$ vs. $0.06(0.02) \mathrm{m}, P \leq 0.05)$. The mean (SD) for WC at mean age of 11 and 12 years was $64.5(1.1) \mathrm{cm}$ and $66.5(1.1) \mathrm{cm}$, respectively, among boys; $64.3(1.1) \mathrm{cm}$ and $65.4(1.1) \mathrm{cm}$ among girls. The mean (SD) for triceps at 


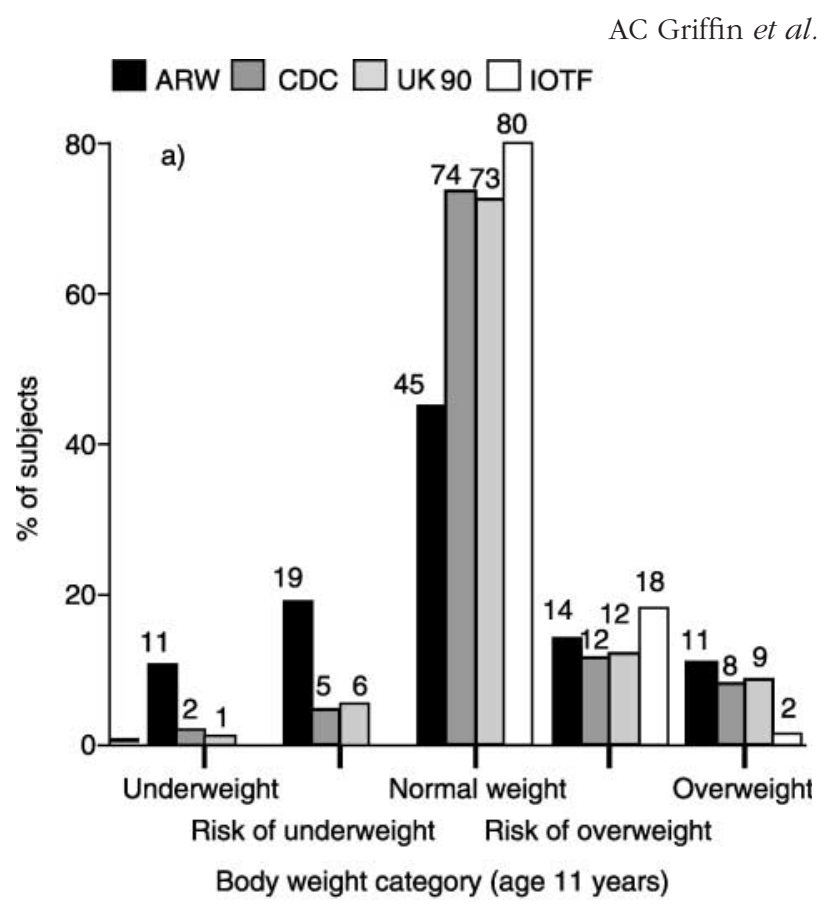

mean age of 11 and 12 years was, respectively, 10.9 (0.2) $\mathrm{mm}$ and $11.3(0.2) \mathrm{mm}$ among boys; $13.4(0.1) \mathrm{mm}$ and $13.9(0.1) \mathrm{mm}$ among girls. Triceps measurements among girls were significantly greater $(P \leq 0.001)$ than among boys at baseline and in the one-year follow-up. Anthropometric measurements did not differ according to SEC classification. At baseline and follow-up, BMI was found to correlate more strongly than ARW to triceps measurements $(r=-0.731$ vs. $r=0.606$ at mean age of 11 years; $r=-0.662$ vs. $r=0.581$ at mean age of 12 years). (It should be noted that the distribution of BMI was skewed and was transformed to give a normal distribution by taking the reciprocal. Therefore, the negative correlation of BMI to triceps demonstrates that as BMI increases so does adiposity.)

The prevalence of overweight varied according to the different criteria currently available, as shown in Fig. 1a for mean age of 11 years and Fig. $1 \mathrm{~b}$ for mean age of 12 years. The prevalence of overweight within the total group differed between criteria by $9 \%$ at baseline and $8 \%$ at follow-up. Positive trends in overweight prevalence in the one-year follow-up therefore ranged from zero to $3 \%$. Using the criterion of the INNS (BMI $\left.\geq 26 \mathrm{~kg} \mathrm{~m}^{-2}\right)^{3}$, it was found that $6 \%$ ( $n=12,95 \%$ confidence interval (CI) $3.15-$ $10.29 \%)$ of the total group, mean age 12 years, were overweight compared with $1.9 \%$ ( $n=4,95 \%$ CI $0.5-4.8 \%)$ of the total group $(n=207)$ in 1990. This indicates a threefold increase (95\% CI $0.3-7.9 \%, P \leq 0.05$ ) among 12 -year-old children over the last 10 years. The prevalence of $\mathrm{BMI} \geq 26 \mathrm{~kg} \mathrm{~m}^{-2}$ did not differ according to SEC classification.

According to ARW, overweight subjects had greater central adiposity than their normal-weight counterparts at mean age of 11 years $(71.2(1.1) \mathrm{cm}$ vs. $63.2(1.1) \mathrm{cm}$, $P \leq 0.001)$ and mean age of 12 years $(71.5(1.1) \mathrm{cm}$ vs. $65.1(1.1) \mathrm{cm}, P \leq 0.001)$. A greater proportion of boys than of girls were found to be underweight (at mean age of 11 years: $36 \%(n=32)$ vs. $25 \%(n=27), P \leq 0.05$; at mean age of 12 years: $44 \%(n=40)$ vs. $20 \%(n=22)$, $P \leq 0.001)$ at baseline and follow-up. Likewise, a smaller proportion of boys compared to girls were found to be overweight (at mean age of 11 years: $17 \%(n=15)$ vs. $32 \%$ $(n=35), P \leq 0.05$; at mean age of 12 years: $21 \%(n=19)$ vs. $30 \%(n=33), P \leq 0.001)$. The occupancy of ARW categories was independent of SEC classification.

According to ARW, approximately half of the total group (47\% $(n=94)$ and 51\% $(n=102)$ at mean age of 11 and 12 years, respectively) perceived their actual body shapes incorrectly (Fig. 2). Over a quarter of the children expressed a preference to be thinner $(29 \%(n=57)$ at mean age of 11 years and $27 \%(n=55)$ at mean age of 12 years). At follow-up, more girls compared with boys expressed the desire for a thinner body shape (39\% ( $n=40)$ vs. $17 \%(n=15), P \leq 0.05)$. Preference towards thinness did not differ according to SEC classification. At baseline and follow-up respectively, overweight children

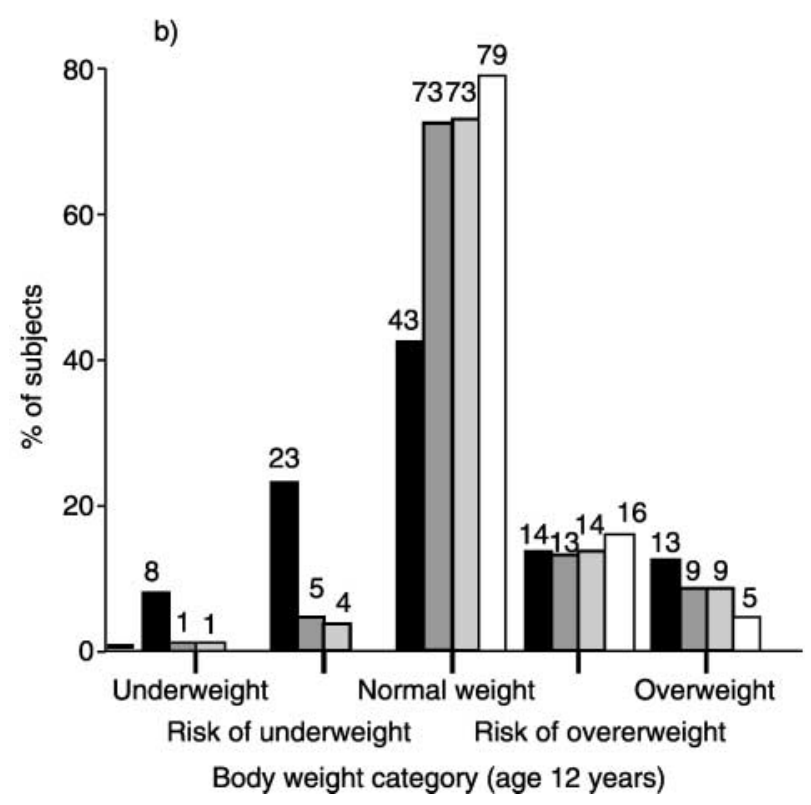

Fig. 1 Proportions (\%) of young adolescent schoolchildren ( $n=199$; 90 boys, 109 girls) assigned to body weight categories according to four different methods of assessment: (a) at mean age of 11 years; (b) at mean age of 12 years. Assessment methods: ARW - actual relative weight ${ }^{10}$; CDC - Centers for Disease Control and Prevention body mass index (BMI)-for-age charts for boys and girls ${ }^{9}$; UK90 - BMI reference curves for the UK $1990^{8}$; IOTF-International Obesity Task Force age- and sexspecific BMI cut-offs ${ }^{6}$

$(58 \%(n=29)$ and 54\% $(n=26))$ were more likely to express a desire for a thinner shape $(P \leq 0.001)$ than their normal-weight $(21 \%(n=19)$ and $32 \%(n=26))$ and underweight $(16 \%(n=9)$ and $5 \%(n=3))$ counterparts.

The same subjects who reported trying to lose weight at baseline also reported trying to lose weight at follow-up. Reports of attempted slimming practices included, at mean ages of 11 and 12 years respectively, eating less fatty foods 


\section{$\square$ Underweight $\square$ Normal weight $\square$ Overweight}
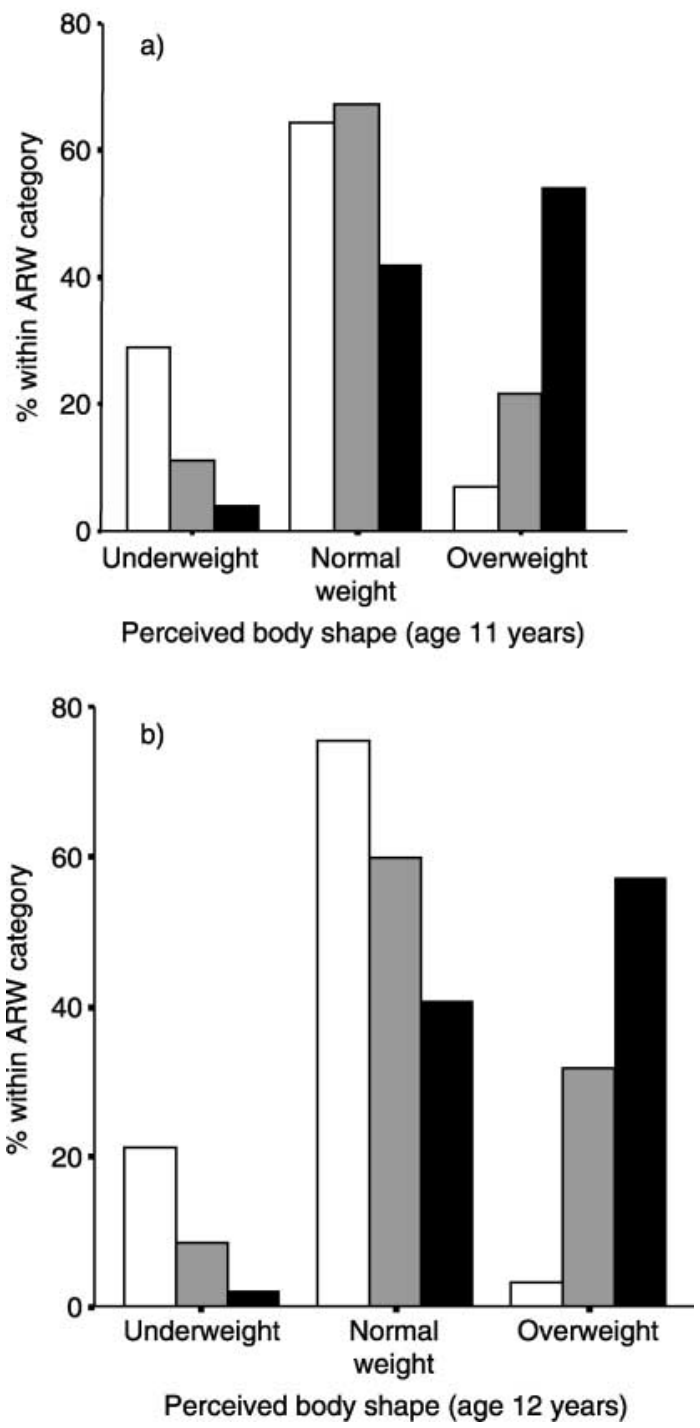

Fig. 2 Proportions (\%) of adolescent schoolchildren within actual relative weight (ARW) categories (underweight, normal weight and overweight) compared with their self-perceived body shape: (a) at mean age of 11 years; (b) at mean age of 12 years

(78\% vs. 66\%), doing more exercise (63\% vs. 68\%) and skipping meals (13\% vs. 14\%). At baseline and follow-up respectively, $14 \%(n=8)$ and $10 \%(n=6)$ of underweight and $30 \%(n=26)$ and $33 \%(n=26)$ of normal-weight subjects reported that they had previously tried to lose weight. Initial and one-year follow-up showed more girls than boys reporting weight-loss attempts $(42 \%(n=45)$ vs. $20 \%(n=17)$ at mean age of 11 years, $P \leq 0.05 ; 41 \%$ $(n=41)$ vs. $21 \%(n=18)$ at mean age of 12 years, $P \leq 0.05$ ). Weight-loss attempts were comparable among the SEC classifications. Although comparable at baseline, at follow-up overweight girls were more likely to desire a thinner body shape than overweight boys $(67 \%(n=20)$ vs. $33 \%(n=6), P=0.051)$ and twice as likely to report that they had tried to lose weight $(70 \%(n=21)$ vs. $32 \%$ $(n=6), P \leq 0.05)$.

\section{Discussion}

The present study indicates that the prevalence of very overweight young Irish adolescents has increased threefold since 1990. This trend is indicated by comparing the current sample with a nationally representative sample assessed over 10 years ago using the same criterion ${ }^{3}$ for defining overweight. However, the current prevalence of overweight was difficult to quantify according to current standards for assessing overweight in childhood and adolescence. The prevalence varied, ranging from 2 to $11 \%$ at baseline and from 5 to $13 \%$ at follow-up, within the same group of young adolescents depending upon which cut-off was applied to weight-for-height data. Accordingly the trend for overweight ranged from zero to 3\% over one year, highlighting the difficulties in assessing changes in weight status among young Irish adolescents. Fear of fatness was found to be prevalent among overweight individuals and among girls in particular. Prevalence of unhealthy weight-loss strategies (skipping meals) increased by $1 \%$, to $14 \%$, in this one-year follow-up study.

The limitations involved in the present study in estimating the change in obesity prevalence since 1990 among young Irish adolescents need to be considered. First, the population in the present study was recruited from inner-city Dublin schools whereas the children in the INNS were a nationally representative sample recruited from schools in urban and rural areas throughout the Republic of Ireland. It is possible that children in inner-city Dublin may have experienced greater increases in overweight prevalence compared with those in a nationally representative sample, thereby lessening the observed increase. Comparisons within or between urban and rural populations were not made in the INNS and therefore differences in weight status that may have existed and may still persist remain unknown. However, the recruitment of schoolchildren in the present study was comparable to that employed by the INNS, who stratified schools attended to account for school type, sex mix, socio-economic and age representation. Furthermore, the measurement techniques for weight and height and type of equipment used by trained personnel of the current study were very similar to those employed by trained dietitians in the INNS ${ }^{3}$. Finally, the reasonable response rate to the present study should ensure a good representation of those invited to take part and assuage bias and inflated variance. The criterion used by the INNS ${ }^{3}$ to assess overweight, irrespective of age and sex, was defined at as BMI cut-off of $26 \mathrm{~kg} \mathrm{~m}^{-2}-$ this actually corresponds to the cut-off for adults (over the age of 18 years $)^{23}$. According to the standard definitions used in this study, it represents the extreme end of overweight status among young adolescents, exceeding the 95th and 98th cut-offs ${ }^{8,9}$ and corresponding with the adult cut-off ${ }^{6}$ of $30 \mathrm{~kg} \mathrm{~m}^{-2}$ at age 12 years for both boys and girls. The results from the current study indicate that this group of children has grown over the last decade. However, this 
positive trend in obesity prevalence was not apparent after one year of follow-up, according to several weight status assessment methods used in this study, which indicates that longer follow-up periods are necessary to detect secular changes in overweight prevalence among children.

The increasing proportion of overweight children reported in the present study is reflected in the growing prevalence of overweight and obesity documented in other industrialised countries ${ }^{1,24,25}$. There are serious health consequences accompanying the rising prevalence of childhood obesity; most notably the increasing trend of paediatric cases of type 2 diabetes ${ }^{26}$. However, assessing the trend in weight status among Irish adolescents represents a particular problem. There are different references of BMI-for-age and sex to choose from for the assessment of body weight status in children and adolescents $^{6,8,9}$. In the present study, cut-offs derived from large samples, and surveys of pooled data collected over a period of time and which employed quality control measures that minimised measurement error, were used to assess BMI data ${ }^{6,8,9}$. The prevalence of overweight and obesity among this sample is perhaps best represented according to the IOTF cut-offs ${ }^{6}$ that provide internationally comparable prevalence rates of overweight and obesity in children that are linked to the widely accepted adult cut-off points of a BMI of 25 and $30 \mathrm{~kg} \mathrm{~m}^{-2}$. Use of IOTF cut-offs for BMI-for-age thus allows for easier followup of paediatric populations through adulthood. But the current IOTF recommendations do not have a cut-off point for underweight since linking to the adult cut-off of $18.5 \mathrm{~kg} \mathrm{~m}^{-2}$ would yield an unacceptably high proportion of children at risk, while, to date, insufficient childhood morbidity evidence exists to suggest that this is valid ${ }^{6}$. However, since weight-loss attempts have been shown to go hand in hand with fear of fatness, even among underweight girls ${ }^{22}$, it is critical to have a criterion of underweight.

A nationally representative sample that reflects secular trends, accounting for economic, nutritional and environmental influences on size and growth potential, is an important consideration ${ }^{8,27}$. Therefore for the assessment of fear of fatness in the present study, ARW based on Irish clinical growth charts ${ }^{10}$ was used. However, the limitations of the Irish clinical growth standards have to be considered. Current wisdom regarding the construction of reference growth charts recommends that statistical smoothing procedures should be applied to transform data at each age to normal distribution ${ }^{28}$. The Irish growth centiles were based on cross-sectional measurements of weight and height, from approximately 100 boys and 100 girls for each year from age 5 to 19 years inclusive, that were smoothed graphically without sophisticated statistical procedures and used to produce longitudinal standards ${ }^{10}$. This methodology falls short of criteria described above for choosing cut-off points of BMI that identify overweight. Furthermore, indices based on relative weight, for example ARW, assume that the amount of body fat is the same irrespective of stature, underestimating the level of obesity in short individuals ${ }^{28}$. In this regard, BMI compared with ARW has a significantly stronger correlation with subcutaneous body fat in adolescents, as was found with the triceps skinfold in this study and others ${ }^{29}$.

Finally, given that an excessive abdominal adiposity, rather than excessive body mass, is associated with adverse health ${ }^{30}$, it is more appropriate to use the indicator that most closely corresponds to risk. Unfortunately, the INNS did not report waist circumference and therefore trends in abdominal fat distribution cannot be assessed. Recent evidence from Great Britain indicates that the increasing trends in waist circumference during the past $10-20$ years greatly exceed those in $\mathrm{BMI}^{31}$. The authors suggest that these trends may represent an accumulation of fat mass that is being obscured by a reduction in muscle mass ${ }^{31}$.

Fear of fatness, expressed as a desire to be thinner, was found to relate to weight-loss attempts and to affect more girls, increasing with age, than boys. Furthermore, two-thirds of overweight girls, compared with one-third of overweight boys, reportedly desired a thinner body shape, with twice as many overweight girls than boys trying to lose weight at follow-up. Comparing the desire to be thinner among young adolescent girls in the present study (39\%, mean age 12 years) with that reported among older adolescent Dublin girls (59\%, mean age 15 years $)^{22}$ suggests that negative body image increasingly pervades girls' progression to womanhood. Whilst avoidance of obesity is recognised as a healthy practice, inappropriate dieting and weight-loss behaviours known to accompany fear of fatness among adolescents, including purging behaviours and the use of tobacco $^{22}$, alcohol and illegal drugs ${ }^{22}$, may actually pose a far greater threat to their health than obesity ${ }^{17}$. In light of this, public health initiatives that aim to tackle the rising trends in obesity must also tackle the negative body image culture that pervades adolescence, particularly among girls. The most successful interventions are likely to be those that recognise that body image dissatisfaction is influenced by many social and environmental factors, including the media, peers and family $^{32,33}$, and promote environments (for example, in schools and communities) that support active living and healthy eating ${ }^{2}$.

A robust and standard method for identification of Irish children and adolescents at risk of overweight is essential for the evaluation of public health strategies that address the serious and growing problem of obesity. The development of health promotion initiatives, such as healthy eating and active living, which prevent overweight among adolescents without exacerbating the fear of fatness, is urgently needed - particularly among older girls and overweight children. 


\section{Acknowledgements}

The authors are grateful to the school staff and children who took part in this study. This work was supported by funding from Irish Sugar plc, An Bord Bia and the Office of Postgraduate Research, Dublin Institute of Technology. We thank Dr John Kearney, Department of Biological Sciences, Dublin Institute of Technology and Dr Debbie McNeil, Calgary Regional Health for assistance with statistical analysis.

\section{References}

1 World Health Organization (WHO). Obesity: Preventing and Managing the Global Epidemic. Report of a WHO Consultation, Geneva, 3-5 June 1997. WHO/NUT/98.1 Geneva: WHO, 1998.

2 Ebbeling CB, Pawlak DB, Ludwig DS. Childhood obesity: public health crisis, common sense cure. Lancet 2002; 360: 473-82.

3 Hurson M, Corish C. Evaluation of lifestyle, food consumption and nutrient intake patterns among Irish teenagers. Irish Journal of Medical Science 1997; 166(4): 225-30.

4 Seidell JC. Obesity: a growing problem. Acta Paediatrica Supplement 1999; 88: 46-50.

5 Roche AF, Siervogel RM, Chumlea WC, Webb P. Grading adiposityness from limited anthropometric data. American Journal of Clinical Nutrition 1981; 34: 2831-8.

6 Cole TJ, Bellizzi MC, Flegal KM, Dietz WH. Establishing a standard definition for child overweight and obesity worldwide: international survey. British Medical Journal 2000; 320: 1240-3

7 Dietz WH, Bellizzi MC. Introduction: the use of body mass index to assess obesity in children. American Journal of Clinical Nutrition 1999; 70(Suppl.): 123S-5S.

8 Cole TJ, Freeman JV, Preece MA. Body mass index reference curves for the UK, 1990. Archives of Disease in Childhood 1995; 73: 25-9.

9 Kuczmarski RJ, Ogden CL, Grummer-Strawn LM, Flegal KM, Guo SS, Wei R, et al. CDC Growth Charts: United States. Advance Data from Vital and Health Statistics No. 314. Hyattsville, MD: National Center for Health Statistics, 2000.

10 Hoey HMCV, Tanner JM, Cox LA. Clinical growth standards for Irish children. Acta Paediatrica Scandinavia 1987; 338 : $2-31$.

11 National Center for Health Statistics (NCHS). Height and Weight for Youths, 12-17 Years, United States. US Department of Health, Education and Welfare Series 11, No. 24. Bethesda, MD: NCHS, 1973.

12 Roche AF. Anthropometrical methods: new and old, what they tell us. International Journal of Obesity 1984; 8: 509-23.

13 Wattigney WA, Webber LS, Srinivasan SR, Berenson GS. The emergence of clinically abnormal levels of cardiovascular disease risk factor variables among young adults: the Bogalusa Heart Study. Preventive Medicine 1995; 24: 617-26.

14 Daniels SR, Morrison JA, Sprecher DL, Khoury P, Kimball TR. Association of body fat distribution and cardiovascular risk factors in children and adolescents. Circulation 1999; 99: $541-5$.

15 Taylor RW, Jones IE, Williams SM, Goulding A. Evaluation of waist circumference, waist-to-hip ratio and the conicity index as screening tools for high trunk fat mass, as measured by dual x-ray absorptiometry, in children aged 3-19 years. American Journal of Clinical Nutrition 2000; 72: 490-5.

16 Flynn MAT. Fear of fatness and adolescent girls: implications for obesity prevention. Proceedings of the Nutrition Society 1997; 56: 305-17.

17 Neumark-Stzainer D, Hannan PJ. Weight-related behaviours among adolescent girls and boys: results from a national survey. Archives of Pediatrics \& Adolescent Medicine 2000; 154: 569-77.

18 Patton GC, Selzer R, Coffey C, Carlin JB, Wolfe R. Onset of adolescent eating disorders: population based cohort study over three years. British Medical Journal 1999; 318: 765-8.

19 O'Hare. A note on a proposed census-based Irish social class scale for epidemiological health research. Economic \& Social Reviews 1982; 13(3): 205.

20 Garrow JS. Composition of the body. In: Garrow JS, James WPT, eds. Human Nutrition and Dietetics, 9th ed. New York: Churchill Livingstone, 1993.

21 Collins ME. Body figure perceptions and preferences among preadolescent children. International Journal of Eating Disorders 1991; 10(2): 199-208.

22 Ryan YM, Gibney MJ, Flynn MA. The pursuit of thinness: a study of Dublin schoolgirls aged $15 y$. International Journal of Obesity and Related Metabolic Disorders 1998; 22: 485-7.

23 Himes JH, Dietz WH. Guidelines for overweight in adolescence preventive services: recommendations from an expert committee. American Journal of Clinical Nutrition 1994; 59: 307-16.

24 Troiano RP, Flegal KM, Kuczmarski RJ, Campbell SM, Johnson CL. Overweight prevalence and trends for children and adolescents. The National Health and Nutrition Examination Surveys, 1963 to 1991. Archives of Pediatrics E Adolescent Medicine 1995; 149: 1085-91.

25 Hughes JM, Li L, Chinn S, Rona RJ. Trends in growth in England and Scotland, 1972 to 1994. Archives of Disease in Childhood 1997; 76: 182-9.

26 Rocchini AP. Childhood obesity and a diabetes epidemic. New England Journal of Medicine 2002; 346: 854-5.

27 Livingstone B. Epidemiology of childhood obesity in Europe. European Journal of Pediatrics 2000; 159(Suppl. 1): $514-34$.

28 Cole TJ. The LMS method for constructing normalised growth standards. European Journal of Clinical Nutrition 1990; 44: 45-60.

29 Malina RM, Katzmarzyk PT. Validity of the body mass index as an indicator of the risk and presence of overweight in adolescents. American Journal of Clinical Nutrition 1999; 70: $131-65$.

30 Pi-Sunyer FX. Health implications of obesity. American Journal of Clinical Nutrition 1991; 53: 1595S-603S.

31 McCarthy HD, Ellis SM, Cole TJ. Central overweight and obesity in British youth aged 11-16 years: cross sectional surveys of waist circumference. British Medical Journal 2003; 326: 624-7.

32 Field AE, Camargo CA, Taylor CB, Berkey CS, Roberts SB, Colditz GA. Peer, parent, and media influences on the development of weight concerns and frequent dieting among preadolescent and adolescent girls and boys. Pediatrics 2001; 107: 54-60.

33 Shapiro S, Newcomb M, Loeb TB. Fear of fat, disregulatedrestrained eating, and body-esteem: prevalence and gender differences among eight- to-ten-year-old children. Journal of Clinical Child Psychology 1997; 26(4): 358-65. 